\title{
La seguridad y la salud en el trabajo. Una aproximación a través del Derecho penal cubano*
}

\author{
Karel Feria Galbán, M. Sc."
}

Recibido: 30 de agosto de 2019 • Aprobado: 20 de noviembre de 2019

\section{Resumen}

En Cuba el derecho de los trabajadores a la seguridad y la salud en el trabajo constituye un principio elemental para el fortalecimiento del derecho de trabajo. Diversas opiniones acuden a si es preciso recurrir al Derecho penal como uno de los que deben salvaguardar ese derecho, a pesar de que hoy resulta el tema interesante por la trascendencia en la que se navega entre la teoría y la práctica legal cubana unido a esto, resalta; el acompañamiento a cada uno de los trabajadores en su rutina diaria de la seguridad y la protección a su salud y que deben ser protegidos por el empleador, teniendo en cuenta lo establecido por el ordenamiento jurídico cubano. Abordar la problemática existente en torno a la seguridad y la salud en el trabajo en Cuba desde sus elementos estructurales y su vinculación ante el riesgo, pasando por los riesgos psicosociales, así como los mecanismos de controly la responsabilidad en el orden laboral devienen ejes centrales en el presente artículo. Teniendo como punto de conexión al Derecho penal para dar respuesta a los hechos más graves partiendo de lo que tenemos, de lo que se adolece y lo que será necesario.

Palabras clave: Seguridad y salud. Riesgo. Riesgo psicosocial. Bien Jurídico.

* $\quad$ El presente artículo es producto del proyecto de investigación "La seguridad ciudadana en el siglo xxı", Universidad de Oriente, Cuba.

Citar como: Feria Galbán, K. (2020). La seguridad y la salud en el trabajo. Una aproximación a través del Derecho penal cubano. Revista IUSTA, 52,15-50. Dor: https://doi.org/10.15332/25005286.5481

** Abogado de la onbc, Máster en Derecho Civil y Familia. Candidato a Doctor en Ciencias Jurídicas. Profesor asistente a tiempo parcial de la Facultad de Derecho de la Universidad de Oriente, Cuba. knoaly81@gmail.com. orcid: 0000-0001-5676-8594. 


\title{
SAFETY AND HEALTH AT WORK. An approach through Cuban criminal laW
}

\begin{abstract}
In Cuba, the workers' right to safety and health at work constitutes an elementary principle for strengthening the right to work. There are different opinions about whether it is necessary to resort to criminal law as one of those who must safeguard that right. Currently, the topic is interesting because of the importance of navigating between the theory and the Cuban legal practice. Together with this, the support to each of the workers in their daily routine of safety and protection to their health is emphasized, and that they must be protected by the employer, taking into account the provisions of the Cuban legal system. The central theme of this article is to address the existing problem regarding health and safety at work in Cuba, from its structural elements and its link to the risk, taking into account psychosocial risks, as well as control mechanisms and responsibility in the labor area. Criminal law will be used as a connection point to respond in the most serious events, based on what we have, what is lacking and what will be necessary.
\end{abstract}

Keywords: legal right, risk, psychosocial risk, health, safety.

\section{A segurança e a saúde no trabalho. UMa aproximaçÃo através do Direito penal cubano}

\section{Resumo}

Em Cuba o direito dos trabalhadores à segurança e a saúde no trabalho constitui um princípio elementar para o fortalecimento do direito ao trabalho. Há diversas opiniões em torno se é preciso recorrer ao Direito penal como um dos que deve salvaguardar este direito. Atualmente o tema resulta interessante pela transcendência na que se percorre entre a teoria e a prática legal cubana. Junto a isto resalta o acompanhamento a cada um dos trabalhadores na sua rotina diária da segurança e proteção a sua saúde e que devem ser protegidos pelo empregador, levando em consideração o estabelecido pelo ordenamento jurídico cubano. $\mathrm{O}$ eixo central deste artigo é abordar a problemática existente em torno à segurança e saúde no trabalho em Cuba, desde seus elementos estruturais e sua vinculação perante o risco, levando em consideração os riscos psicossociais, assim como os mecanismos 
de controle e responsabilidade na ordem trabalhista. Se terá ao Direito penal como ponto de conexão para responder aos fatos mais graves, partindo do que temos, do que carece e do que será necessário.

Palavras-chave: bem jurídico, risco, risco psicossocial, saúde, segurança.

\section{Introducción}

El hombre a través de su historia ha tenido necesidad de alimentarse para sobrevivir. Su marcado interés al trabajo inicial, su preocupación por tener cada día los alimentos indispensables para subsistir lo hicieron defenderse de las adversidades propias de la naturaleza circundante.

Se asume que "el trabajo es parte integrante de la condición humana, aunque no es la única razón de la existencia” (Bayo Mayor, 2017, p. 44; La Biblia, 1995, pp. 498-499). De tal modo, que los seres humanos al vivir en sociedad", "tienen la necesidad de sobrevivencia y de obtener sus bienes a través del trabajo" (Moreira, 2003, p. 1).

Si bien la sociedad humana, ha cambiado cualitativa y cuantitativamente de acuerdo con las diferentes circunstancias de lugar y de tiempo; también es cierto, que gradualmente ha pasado de ser una sociedad simple a una compleja estructura donde todo se transforma, cambia, deviene y deja de ser. De igual forma ha sido el trabajo -que etimológicamente se deriva del latín tripalium² (López Sánchez, 2017, pp. 29-30) - una palabra considerada en sus inicios con una carga negativa, para después en algún momento de la historia, aparecer con un sentido positivo, como faceta activa de la vida humana, a través de la cual el hombre - trabajador se realiza y participa como protagonista de los beneficios del progreso moral y material de la humanidad (Callizo, 2014, p. 2).

Con la introducción del maquinismo y la concentración de trabajadores en grandes fábricas, y la exaltación del beneficio empresarial, fue el leitmotiv que condujo al crecimiento de los accidentes y enfermedades laborales. Al decir de Montoya Melgar y Pizá Granados (2000), sostienen que, en los albores de esta

1 NA: Entendida ésta como un conjunto, unidos moral, material, espiritual y culturalmente para la satisfacción de comunes necesidad, recíprocos beneficios, aspiraciones semejantes y fines iguales.

2 NA: Esto era una especie de cepo para sujetar las patas de los animales, con el fin de herrarlos, también constituyó un instrumento de suplicio para fugitivos o prisioneros. Por lo cual la palabra trabajar, derivado del latín popular tripalliare, dignificaba atormentar, torturar con el tripalium. 
problemática, una primera actitud ante la siniestralidad laboral fue la de reputarla como algo normal e inevitable, estimándose que el trabajador, por el hecho de aceptar un determinado trabajo, asumía los posibles riesgos que éste comportara. Ello explica que, durante mucho tiempo, pese al elevadísimo número de accidentes y enfermedades de trabajo, los trabajadores damnificados o sus derechohabientes no pensaran siquiera en la posibilidad de reclamar a sus patronos indemnizaciones por los daños y perjuicios sufridos (pp. 13-14).

Diríamos que ese momento de la historia -referido anteriormente-, es ubicado al inicio de la Revolución Industrial -segunda mitad del siglo xviı- hasta la aprobación de la Declaración Universal de los Derechos Humanos en el año $1948^{3}$ (Organización de Naciones Unidas [onU], 1948), que es donde se comienza a considerar al trabajo, en otros términos. Más que como un simple generador de bienes y productos, se calificaba como un derecho (López Sánchez, 2017, p. 30).

La aparición de la legislación laboral entre las que podemos citar de "Health and Morals of Apprentices Act", del año 1802; las leyes de 1833, sobre trabajos de menores y la de 1847 sobre trabajo de mujeres y menores, todas creadas en Inglaterra ${ }^{4}$, constituyó una de las respuestas que el sistema social arbitra frente al conjunto de problemas socioeconómicos planteados a partir de la Revolución Industrial; respuesta que - conviene participar - surge de una compleja y difícil conjunción de fuerzas políticas y sociales, de acciones y reacciones cuyos protagonistas básicos son, junto con el poder público y las elites intelectuales reformistas, los trabajadores y patronos y sus respectivas organizaciones (Montoya Melgar, 2017, p. 30). También aparecen las primeras normas penales ${ }^{5}$ (Soto Calderón, 1961, pp. 47-49), las que se

3 Precisamente el artículo 23 del propio texto en su primer apartado reseña que "toda persona tiene derecho al trabajo, a la libre elección de su trabajo, a condiciones equitativas y satisfactorias de trabajo y a la protección contra el desempleo".

4 Entre otros ejemplos podemos enunciar en los Estados Unidos de América para el año 1898 se estableció la responsabilidad económica del empresario por accidente laboral, y más tarde; para el año 1911 se aprobó la primera ley que obligaba a indemnizar al trabajador. De igual forma en España, a principios del siglo xx (año 1900) se promulgó la Ley de Accidentes de Trabajo.

5 La Ley Le Chapellier de 1791 en Francia, que prohibía las asociaciones profesionales y penó la huelga como delito; los códigos penales de Alemania, 1870 e Italia de 1890, que reconocían la libertad de trabajo y asociación, considerando delitos sólo los atentados contra éstas. El Código Penal Italiano de 1930 estableció, como secuela jurídica de la economía corporativa una completa regulación penal de las materias laborales, consagrándoles un título denominado "Delitos contra la economía pública, la industria y el comercio". Tendencia similar fue la de la legislación alemana de esa misma época. Por último, en la extinta Unión de Repúblicas Socialistas Soviéticas, en su primer código penal después del triunfo de su revolución se estableció como figura delictiva los atentados contra la economía y las infracciones a las leyes del trabajo. 
encontraban encaminadas a la penalización de actos relacionados con la suspensión de labores y atentatorios contra la libertad de trabajo.

Es así que, con la incorporación de las llamadas cláusulas sociales y económicas en los textos constitucionales (Cabanellas, 1949, pp. 540 y ss) de México de 1917, de Weimar de 1919, de España de 1931 y la de la extinta Unión de Repúblicas Socialistas Soviéticas de 1936; señalan una modificación de conceptos; pues en tanto que prevalecían, en tiempos de antaño las consideraciones de carácter político, es el momento donde se adquieren especial significación las referentes a la libertad económica, consagrantes del derecho al trabajo y del derecho del trabajo como prerrogativas junto a las más importantes declaraciones de orden político que los textos constitucionales insertan. Así que se desarrolla en esos años el fenómeno de la constitucionalización del Derecho Social, a través de los modernos magnos textos en los cuales se introducen cláusulas de carácter económico y laboral. Teniendo su fuente directa de inspiración en las recomendaciones adoptadas por la Organización Internacional del Trabajo, relativas tanto al ámbito laboral y en especial atención a la prevención de accidentes del trabajo como la de las enfermedades profesionales.

En la actualidad dentro del derecho del trabajo se desprende el reconocimiento a favor de los trabajadores de un específico derecho, relacionado con la seguridad y la salud en el trabajo significándose que el legislador otorga una relevancia y tutela específicas al interés privado y extrapatrimonial propio del trabajador en disfrutar de unas condiciones de trabajo seguras para su vida, su integridad y su salud, al margen e independientemente del interés general y público que al mismo tiempo concurren en la materia de la seguridad y la salud en el trabajo (Martín Hernández, 2006, p. 15). Cuyo componente resulta de interés común para toda la sociedad, debido al auge de actividades laborales que como todas poseen un mayor o menor grado de riesgo para el trabajador.

La siniestralidad laboral -término que se desprende de la desatención hacia la seguridad y la salud en el trabajo-, es un problema mundial que afecta no solo a los países industrializados, sino también a los que se encuentran en vías de desarrollo y a los "subdesarrollados". En efecto, la existencia de relaciones laborales y consigo el desempeño de actividades productivas generadoras de riesgos, es una característica ineludible al progreso económico de las sociedades. Fenómenos como la globalización, tecnificación, informatización, outsourcing, la reestructuración organizacional y el downsizing, han posibilitado un cambio en las reglas del mercado y, por tanto, la incorporación de nuevas formas de producción y riesgos que suelen afectar los 
bienes jurídicos esenciales de los trabajadores (Ramírez Barbosa, 2007, p. 34). Riesgos que son entendidos, en su oposición a los dramas naturales que siempre han asaltado a la humanidad, como un peligro generado por decisiones sociales, derivadas de las ventajas y oportunidades generadas industrialmente.

Pero, al decir de Arroyo Zapatero (1996), el riesgo para la vida y la seguridad derivado de la industrialización no fue sino el primero de los grandes procesos de riesgo que habrían de insertarse en la vida cotidiana de los hombres y del Derecho de la sociedad moderna sino que habría que incluir otros tres grandes factores de riesgo: el tráfico automovilístico, el de la energía nuclear y el derivado de la aplicación masiva e intensiva de la química y de la biología industrial y su proyección sobre el medio ambiente (p. 4). Estos factores han conformado materialmente a las sociedades postindustriales como sociedades de riesgo, en las que el sometimiento al riesgo ${ }^{6}$ (Beck, 2002, p. 120) no es la excepción, sino la regla general de la vida cotidiana $^{7}$ (Arroyo Zapatero, 1996, p. 4; Beck, 2008, pp. 255 y ss).

Es así que, en la actual sociedad de riesgo, el Estado no puede limitarse a garantizar al individuo un espacio de autonomía que impida la injerencia de terceros en su esfera de libertad, mediante el reconocimiento formal de una serie de derechos en su favor, sino que debe garantizar igualmente el libre y efectivo desarrollo de su personalidad en la sociedad, mediante el establecimiento de todos aquellos mecanismos que permitan su participación en condiciones de igualdad material. Mecanismos entre los que tiene que ocupar un lugar destacado la protección de los bienes jurídicos supraindividuales por medio de los delitos de peligro, prestando especial atención a aquellos grupos sociales que, por encontrarse en una franca situación de desigualdad, requieren una protección reforzada (Gallo, 2014, p. 32).

6 NA: Sostiene Beck —el teórico de la sociedad de riesgo—, que como resultado también puede captarse con mayor claridad la diferencia que marca época y distingue los riesgos de la sociedad industrial y del orden social burgués de los peligros y exigencias de la sociedad del riesgo. El acceso a la sociedad del riesgo se produce en el momento en el que los peligros que la sociedad decide ahora y produce consecuentemente socavan y/o anulan los sistemas de seguridad establecidas por el cálculo de riesgos existente en el estado de bienestar.

7 Arroyo Zapatero referencia a Beck, en el sentido plantea los cuatro tipos de problemas que la sociedad de riesgo presenta y da respuesta entre los cuales se encuentra: $10^{\circ}$ el problema sociológico de interiorización y aceptación social del proceso de riesgo; $2 .^{\circ}$ el problema político del manejo de la conciencia de riesgo por parte de los ciudadanos; $3 .^{\circ}$ el problema económico del costo de los daños y el costo de los productos; $44 .^{\circ}$ el problema jurídico del tratamiento normativo del control de las fuentes de riesgo y de la determinación de las consecuencias de la realización del riesgo en lesión. 
El derecho a la seguridad y la salud en el trabajo tiene un origen contractual entre el trabajador y el empleador, siendo este último el sujeto obligado a satisfacerlo por ser la contraparte del vínculo jurídico en el que tiene su origen. Es en la figura del empleador que recae el deber correlativo de proporcionar a cada uno de los trabajadores con los que se encuentra vinculado por medio de una relación jurídica de naturaleza laboral una protección eficaz en materia de seguridad y la salud en el trabajo y satisfacer de ese modo el interés privado de todos y cada uno de ellos en trabajar en unas condiciones seguras para su vida, su integridad física y psíquica y su salud - al margen de que al mismo tiempo también satisfaga intereses propios de naturaleza estrictamente patrimonial- (Martín Hernández, 2006, pp. 16-17). O sea, si no cumple con tal deber estará incumpliendo sus obligaciones contractuales e incurrirá en la correspondiente responsabilidad frente a los concretos trabajadores afectados por tal incumplimiento.

Es en este contexto, la intervención penal en el ámbito de la prevención de riesgos laborales contribuiría a reequilibrar la situación de subordinación y dependencia en la que se encuentra el trabajador respecto al empresario como consecuencia del vínculo contractual que los une (Hortal Ibarra, 2004, pp. 237-251). Por ende, contribuiría a deslindar la responsabilidad que pudiera ser exigible al empresario y a los trabajadores.

Esa intervención en el ámbito de la seguridad y la salud en el trabajo parte de la constatación de una realidad fáctica ${ }^{8}$. La que al ser comparada no se corresponde con lo que habitualmente pudiera conocer los órganos jurisdiccionales, por lo que

8 NA: Según datos de la Organización Internacional del Trabajo (оiт, 2005, 2007), cada día mueren en el mundo alrededor de 6000 trabajadores, destacándose que aproximadamente 2 millones de muertes en el año, teniendo como causas los accidentes de trabajo y enfermedades profesionales. Se estima que la tasa anual global de accidentes del trabajo mortales y no mortales se eleva a 270 millones. En los años 2015-2016; el propio ente internacional expone que cada 15 segundos muere un trabajador a causa de accidentes o enfermedades relacionadas con el trabajo, al año en el mundo ocurren 250 millones de accidentes laborales de ellos mueren 2,3 millones de trabajadores en el trabajo, mientras que otros 317 millones de trabajadores son víctimas de accidentes relacionados con el trabajo. Por su parte en Cuba según datos estadísticos, un total de 48 familias sufrieron hasta octubre de 2014 la pérdida de uno de sus miembros como consecuencia de un accidente laboral, cuyo número implica la disminución en 8 con respecto al pasado período, aunque la cifra fue de 70 trabajadores que perdieron la vida al cierre del año. Si le adicionamos el padrón con respecto a los lesionados a pesar de haber disminuido sigue siendo una cuantía numerosa de 3407 a 2646 el número de lesionados. Como principales causas se encontraba los incumplimientos de los directivos, principalmente en sus responsabilidades organizativas, conductas temerarias y negligentes relacionadas con la seguridad vial (Manguela Díaz, 2015; Manguela Díaz, 2017; Jasán Nieves, 2015; Bosch Taquechel, 2017). 
surge una resistencia hacia lo penal. Sin embargo, la respuesta es que no se trata de pretender la transformación de la ley penal en herramienta emancipadora o superadora de desigualdades sociales históricas (Gallo, 2014, p. 36). Sino de crear presupuestos teóricos para que el legislador pueda prestar mayor atención aquellos bienes jurídicos de mayor gravedad y en peligro en el marco de la relación laboral.

Nuestro país como bien lo reafirma el primer artículo de nuestra Constitución es un Estado Socialista de trabajadores, independiente y soberano, de tal forma que el trabajo constituye derecho, deber y un motivo de honor para cada ciudadano, de ahí la defensa al descanso laboral, a la jornada de ocho horas y a la protección, seguridad e higiene del trabajo; estando plasmado en nuestra ley de leyes ese derecho de segunda generación nacido con la revolución industrial y que conlleva al Estado la obligación de hacer a favor de los derechos laborales, ampliando la esfera de su responsabilidad imponiendo un deber hacer positivo por parte de ello, encontrándose como parte de esa responsabilidad el ejercicio penal contra los delitos laborales.

Al observar los índices de accidentabilidad laboral ${ }^{9}$, muestra una realidad que ha sido preocupación total de los que intervienen en su prevención, adoptándose medidas jurídicas y extrajurídicas encaminadas a la salvaguardar los intereses de los trabajadores frente a los riesgos derivados del trabajo y, por tanto, una mayor actuación del Estado en la tutela de la seguridad y la salud en el trabajo.

A pesar de tener esos índices de accidentabilidad, se cuenta con instrumentos jurídicos que no muestran total vínculo con la problemática en cuestión, ya sea por su vigencia en el tiempo o por el contenido en sí. Dentro de esas referidas normas se encuentra, el actual Código de Trabajo y su reglamento y las demás disposiciones ministeriales ${ }^{10}$ (Ley N. ${ }^{\text {116 }}$, 2013; Decreto N.o 326, 2014), y el vigente Código Penal en su artículo 296, el que ha dejado por sentado el interés estatal en proteger los derechos laborales ante el incumplimiento de normas de protección e higiene del trabajo; cuestión que analizada, en el ámbito actual del desarrollo se

$9 \quad$ Nota N.o 8.

10 NA: Entre ellas se encuentran: El Ministerio de la Agricultura relacionado con los requisitos de seguridad en el trabajo de la maquinaria agrícola y para la importación, fabricación, montaje, explotación, mantenimiento y reparación de las máquinas herramientas para elaborar madera; el Ministerio de la Construcción para la construcción civil y montaje, el Ministerio de Energía y Minas sobre la seguridad minera y la eléctrica, el Ministerio de Industria para la explotación de los equipos generadores de acetileno, para la explotación segura de los recipientes a presión, para los equipos de soldadura, para la explotación segura de las máquinas herramientas industriales y para la instalación, explotación y mantenimiento de las calderas de vapor y el Ministerio de Transporte sobre la explotación de medios de izado. 
ha convertido en una norma, poco utilizada por los operadores jurídicos y por ende resulta incoherente a su propia protección.

\section{Elementos estructurales}

\section{de la seguridad y la salud en el trabajo}

Para poder realizar un análisis efectivo sobre la seguridad y salud en trabajo como objeto de protección en el ámbito penal es preciso adentrarse a los elementos que desde el Derecho laboral la integran y que sirve de sustento en la construcción o configuración de esta.

Para ello, es válido señalar los argumentos dados por diversos autores ${ }^{11}$ los que saltan a la vista con diversas denominaciones, donde se utilizan términos como seguridad e higiene en el trabajo, seguridad y salud en el trabajo, seguridad en el trabajo, seguridad o salud en el trabajo, salud ocupacional e higiene y seguridad ocupacional, siendo los más frecuentes en el orden laboral los dos primeros, sin embargo; al contrastarse con las leyes sustantivas penales ${ }^{12}$ no existe una coherencia con la denominación, se asumen como bien jurídico la vida y la integridad personal y solo en dos, El Salvador y Nicaragua hacen referencia a la protección de los derechos laborales y en pocos delitos se refieren a la seguridad y salud de los trabajadores.

En tal sentido vale destacar algunas definiciones en torno al tema. Lascurain Sánchez (1994) asevera, que la seguridad e higiene en el trabajo designa la ausencia de riesgo para la vida, la integridad física y la salud de los trabajadores proveniente

11 Tales como: Sara Aguado López, Luis Arroyo Zapatero, Juan Carlos Hortal Ibarra, Juan Antonio Lascurain Sánchez, Alfredo Montoya Melgar, Jaime Pizá Granados y Paula Andrea Ramírez Barbosa.

12 NA: Se tomó como muestra los códigos de trabajo y penal de los siguientes países: Chile, Colombia, Costa Rica, Ecuador, El Salvador, Guatemala, Honduras, México, Nicaragua, Panamá, Paraguay, Perú, República Dominicana y Uruguay, donde confluyen como común denominador un mismo sistema de derecho. (Código del Trabajo de Chile, 2002; Código Sustantivo del Trabajo de Colombia, 1950; Código de Trabajo de Costa Rica, 1943; Código del Trabajo de Ecuador, 2005; Código de Trabajo de El Salvador, 1972; Código de Trabajo de Guatemala, 1961; Código del Trabajo y sus reformas de Honduras, 1959; Ley Federal del Trabajo de México, 2015; Código del Trabajo de Nicaragua con sus reformas, adiciones e interpretación auténtica, 1996; Código de Trabajo de Panamá, 1995; Ley N.o 213; Código del Trabajo de Paraguay, 1993; Ley N.o 496, 1995 Ley General del Trabajo de Perú, 2006; Código de Trabajo de República Dominicana, 1992; Compendio normativo en materia de Seguridad y Salud en el Trabajo del Uruguay, s. a.; Compendios de Códigos Penales, s. a.) 
de las condiciones materiales, personales y organizativas de realización de su prestación (p. 27).

Aguado López (2002) en similar línea de pensamiento apunta que, la seguridad e higiene en el ámbito laboral engloba la protección de la vida, salud e integridad física del trabajador, el bienestar y comodidad en el trabajo, así como la adecuación personal del hombre al trabajo ${ }^{13}$ (p. 45).

Ramírez Barbosa (2007) manifiesta que la expresión seguridad y salud en el trabajo puede ser entendida como el conjunto de condiciones organizativas, fácticas y personales existentes en una empresa, que tratan de prevenir los riesgos derivados del trabajo y consigo la siniestralidad laboral. Por tanto, este tipo de condiciones están encaminadas a salvaguardar la vida, salud e integridad física y psíquica de los trabajadores, permitiendo de tal forma un desenvolvimiento más humano e íntegro de las relaciones laborales (pp. 54-55).

Por último, sostiene Franco González (2015):

Que la expresión más razonable a utilizar es la de seguridad y salud laboral, definiéndolas como aquellas actuaciones sobre las condiciones de trabajo que pretenden prevenir cualquier tipo de riesgo laboral (físico o psíquico) y promocionar, a la vez, la salud de los trabajadores, entendiéndose el carácter multidisciplinar de la seguridad en el trabajo, la higiene industrial, la ergonomía, la psicosociología aplicada y la medicina del trabajo, supone un valor añadido en la lucha contra la siniestralidad laboral, la cual demanda, sin lugar a dudas, una acción coordinada. (p. 28)

Es evidente que dentro de los términos enunciados resalta el de higiene como parte de la protección a la vida, integridad y salud de los trabajadores. Siendo entendida en dos sentidos, el primero como la previsión de las enfermedades resultantes del ejercicio de una actividad laboral (Ramírez Barbosa, 2007, p. 55). Y la segunda como la rama de las ciencias médicas que tiene, como objetivo crear o mantener las condiciones óptimas para la vida del hombre, y logra que el individuo y la población

13 Sostiene la autora que esa definición está diseñada teniendo en cuenta el artículo 1 de la Ordenanza General de Seguridad e Higiene y 93 de la Ley General de Seguridad Social, sustituidos por el artículo 5 de la Ley de Prevención de Riesgos Laborales y artículo 108.3 de la Ley General de Seguridad Social. 
en general disfruten de adecuada salud ${ }^{14}$ (Cruz Trujillo y Senarega Coca, 2012, p. 2; Hortal Ibarra, 2005, p. 35).

Siguiendo este orden al hacer referencia a la seguridad e higiene en el trabajo, esta se relaciona con medidas preventivas destinadas a la protección de la salud del trabajador. Lo cual requiere, de una parte, la adopción de las medidas médicohigiénicas encaminadas a prevenir las enfermedades profesionales, y, de otra, la prevención de los accidentes laborales, todo ello a través del acogimiento e implementación en la empresa de los mecanismos necesarios de prevención (Montoya Melgar y Pizá Granados, 2000, p. 24).

Por tanto, la expresión seguridad e higiene en el trabajo hoy en día, ha sido sustituida por la fórmula seguridad y salud en el trabajo, principalmente por el contenido más amplio de la segunda expresión a tono con las recomendaciones de la Organización Internacional del Trabajo a través del Convenio N. ${ }^{\circ} 155$ de 1981 (Organización Internacional del Trabajo [отт], 1981).

Así pues, el origen de la responsabilidad del empleador relativa a la seguridad en el trabajo tiene su punto de partida con la apertura de la entidad como fuente de riesgo y su propia intromisión. En este caso la entidad adoptará medidas de seguridad acorde al tipo de actividad que desarrolla según su objeto social y el grado de riesgo que encierre en ella.

En tanto, la seguridad en el trabajo abarca la prevención y control de los riesgos laborales en los diversos momentos de la actividad productiva. La cual se desglosa en primer lugar con la identificación de peligros, evaluación y control del riesgo en la entidad para de esta forma analizar la probabilidad de concreción del peligro ${ }^{15}$ y la posible vulneración del bien jurídico de los trabajadores, permitiéndose la confección de un plan de prevención de riesgos laborales.

Por ende, la seguridad en el trabajo consta de medidas personales, técnicas y psicosociales en la entidad. Las que engloban medidas de carácter médico y de formación que se realzan a través de la instrucción de los trabajadores en la prevención y control de los riesgos laborales. De igual forma se unen a ella las medidas técnicas,

14 Susutenta Hortal Ibarra que la utilización del término "higiene" en la denominación que da nombre a dicha disciplina es atribuible a su gran peso histórico, y particularmente a la gran divulgación que tuvieron los estudios de los médicos higienistas en el transcurso del siglo XIX.

15 "El peligro se conceptualiza como la situación de riesgo inminente por alteraciones de tipo técnico o por intervención humana. Es un riesgo que ofrece posibilidades de que se origine un accidente de forma inmediata con posibles consecuencias graves”(López Gandía y Blasco Lahoz, 2004, p. 23). 
las que se logran por medio de la seguridad industrial, la higiene y la ergonomía ${ }^{16}$, las que a su vez permiten examinar desde la práctica los efectos que tienen o pueden llegar a representar para los bienes jurídicos del trabajador determinados factores físicos o químicos vinculados con el desarrollo de su labor y por último las medidas psicosociales, las que tienen como objeto el estudio de las condiciones de trabajo y su repercusión en el bienestar físico, mental y social de los trabajadores (López Gandía y Blazco Lahoz, 2004; Ramírez Barbosa, 2007).

La presencia del riesgo en las entidades se encuentra latente en toda la actividad laboral, por lo cual la existencia de medidas de seguridad es una condición necesaria para prevenir los riesgos laborales y establecer el contorno de los riesgos permitidos en el ejercicio laboral. Cuyo objetivo no es más que el soslayado en la prevención y reducción de los riesgos, y consigo la tutela de la vida, salud e integridad de los trabajadores.

En suma, la presencia del riesgo en las empresas es una constante en el ejercicio de la actividad laboral en los diversos sectores de la producción, por lo cual la existencia de las medidas de seguridad es una condición necesaria para prevenir los riesgos laborales y determinar el ámbito de los riesgos permitidos en el ejercicio de las actividades productivas. Lo que persigue la implementación de las medidas de seguridad, más que garantizar la ausencia total del riesgo, es la prevención y aminoración de estos, y consigo la tutela de la vida, salud e integridad de los trabajadores (Ramírez Barbosa, 2007, p. 59).

En cuanto a la salud, es entendida como ausencia de enfermedad y, por tanto, como un estado del ser orgánico caracterizado por la aptitud para ejercer normalmente todas sus funciones (Lascurain Sánchez, 1994, p. 27; Igartua Miró, 2011, p. 24). Para el Convenio N. 155 de la Organización Internacional del Trabajo (oIt, 1981), el termino salud, en relación con el trabajo, abarca no solamente la ausencia de afecciones o enfermedad, sino también los elementos físicos o mentales que afectan a la salud y están directamente relacionados con la seguridad e higiene

16 NA: La ergonomía suele definirse como un conjunto de técnicas de carácter multidisciplinar cuyo objetivo es la adaptación del trabajo a la persona a través, fundamentalmente, del diseño y concepción de los puestos de trabajo, ajustados a las características fisiológicas y antropométricas del trabajador (talla, constitución, edad, sexo, agudeza visual y otras análogas). Con ello se busca, principalmente, el logro de una mayor y mejor racionalización de las tareas y el más alto grado de confort posible para el trabajador en el desempeño de las mismas y todo ello con la finalidad última de evitar la afectación de la salud (física, mental o social) como consecuencia del desempeño del trabajo. 
en el trabajo. En esta línea se mueve también la Organización Mundial de la Salud (Pérez Porto y Merino, 2008), que define la salud en términos de estado de bienestar físico, mental y social, es decir, el concepto de salud no solo da cuenta de la no aparición de enfermedades o afecciones, sino que va más allá de eso.

De esta forma, puede afirmarse el carácter dinámico, complejo y polivalente de la noción de salud, en la que se engloban todos los bienes enumerados bajo expresiones como tutela de la vida y de la integridad física y moral del trabajador (Igartua Miró, 2011, p. 24).

Por lo que podemos considerar que el concepto de salud en el trabajo es el estado óptimo al cual se quiere llegar, amparando al trabajador frente a la existencia de posibles enfermedades y de riesgos profesionales que afecten el normal desempeño de las funciones laborales (Ramírez Barbosa, 2007, p. 60).

Sin embargo, según la postura prevencionista los esfuerzos no quedan en el mero hecho conceptual sino van más allá hacia la "promoción de la salud", que aboca la definición de salud laboral integral, motivo por el que la denominación de salud laboral resulta hoy en día imprescindible para entender los cimientos sobre los que se sustenta la actual prevención de los riesgos laborales. No obstante, pese a la consolidación de la expresión en el ámbito preventivo, hablar de salud laboral podría llevar a equívocos, pues carente del término de seguridad -o de otro similar-, es posible que pueda dar la sensación de no abarcarse una parte de la materia que, además, es la que le da sentido técnico (Franco González, 2015, p. 27; Organización Mundial de la Salud [oms], s.a.; Enciclopedia de Conceptos, 2017).

En tanto la normativa dirigida a la protección de los derechos de seguridad y salud en el trabajo estará encaminada a los empresarios como garantes de los derechos de sus trabajadores, para que estos adopten todas las medidas necesarias para ejecutar las políticas y programas de prevención y control de los riesgos laborales.

En efecto, la protección de la vida, salud e integridad de los trabajadores se encuentra directamente vinculada con la seguridad en el trabajo. El interés colectivo de los trabajadores a que existan se implemente y garanticen las medidas de seguridad en la empresa coincide fundamentalmente con el interés individual de cada trabajador a que su salud no sea puesta en peligro como consecuencia de la omisión de las normas de prevención de riesgos laborales que garantizan la existencia de condiciones de seguridad en el trabajo.

De manera que, la seguridad en el trabajo concuerda con la protección de la salud de los trabajadores, ya que uno de los objetivos de aquéllas se relaciona con 
la existencia de condiciones óptimas en el lugar de trabajo que permitan al trabajador el desenvolvimiento efectivo de sus derechos básicos dentro de los que se destaca la salud (Ramírez Barbosa, 2007, p. 63).

Finalmente, somos del criterio que la protección de la seguridad y la salud en el trabajo será imprescindible para su desenvolvimiento; la implementación, aplicación, actualización y constante control de las medidas de prevención y así lograr la reducción de los riesgos laborales en la entidad con la observancia de las disposiciones contenidas en la instrumentación jurídica laboral, convenios colectivos de trabajo y en los propios contratos individuales en lo que respecta a la prevención de accidentes laborales. Todas estas medidas están dirigidas a sostener la protección cierta de los bienes jurídicos procedentes de la existencia de una relación jurídica-laboral por parte del empleador.

\section{La seguridad y la salud en el trabajo ante el riesgo}

Luceño Moreno, Martín García, Rubio Valdehita y Jaén Díaz (como se citó en огт, 2006) asumen el concepto dado por la оіт, al indicar que el trabajo decente resume las aspiraciones de los individuos en lo que concierne a sus vidas laborales, e implica oportunidades de obtener un trabajo productivo con una remuneración justa, seguridad en el lugar de trabajo y protección social para las familias, mejores perspectivas para el desarrollo personal y la integración social, libertad para que los individuos manifiesten sus preocupaciones, se organicen y participen en la toma de aquellas decisiones que afectan a sus vidas, así como la igualdad de oportunidades $\mathrm{y}$ de trato para mujeres y hombres.

Hoy en día nadie discute, que el trabajo resulte una actividad imprescindible para el ser humano que requiere de un esfuerzo físico o intelectual. Aunque suele considerarse que dicha actividad tiene una positiva influencia en ellos, ya que sirve como instrumento al progreso de capacidades físicas e intelectuales, contribuye a la autorrealización y al desarrollo de la personalidad, permitiendo satisfacer sus necesidades más inmediatas y establecer relaciones sociales, también puede tener repercusiones negativas, en especial en relación con la salud. Y ello debido a que las condiciones en que se presta el trabajo originan riesgos laborales que pueden provocar enfermedades y daños a la salud de los trabajadores. (Igartua Miró, 2011, p. 23)

Por lo que promover una motivación suficiente y actitud positiva para adquirir costumbres y hábitos adecuados para evitar las situaciones de riesgos, repercutirá en 
una menor siniestralidad laboral, entiéndase por esta como sinónimo de accidente de trabajo, por lo tanto, será el hecho repentino relacionado casualmente, con la actividad laboral y que produce lesiones, y la consecuente disminución o anulación de la integridad física o fisiológica de la persona trabajadora.

Si bien uno de los objetivos fundamentales de cualquier entidad laboral es de tipo económico, con sus diversas variantes, cobra vital importancia la productividad y para ello es necesario evitar perjudicar la salud y la seguridad de los trabajadores ya que el bienestar de la clase obrera repercuta positivamente en los aspectos cualitativos del trabajo y, por tanto, van a incidir de forma positiva sobre aquella. (Igartua Miró, 2011, pp. 23-24)

Para poder llevar una adecuada actividad preventiva es necesario conocer la naturaleza del trabajo y los factores que influyen en él. Bajo esa visión global podremos identificar y prevenir los riesgos. La acción preventiva no puede ser puntual ya que tanto el trabajo, como las funciones de los trabajadores o incluso el estado de los trabajadores, pueden variar, la acción preventiva es un proceso dinámico y constante. Hay que desarrollar acciones preventivas contra todos los riesgos identificados para poder evitar el accidente laboral o la enfermedad profesional, por lo que es un fin el prevenir los riesgos laborales.

Siendo así, para conceptualizar los riesgos laborales es preciso partir del significado dado por la Real Academia Española de la Lengua (RAE, 1996) en la que expresa que el riesgo es la posibilidad de un daño, perjuicio o inconveniente.

Para Luhmann, el concepto de riesgo ser refiere a la posibilidad de daños futuros debido a decisiones particulares. Las decisiones que se toman en el presente condicionan lo que acontecerá en el futuro, aunque no se sabe de qué modo. El riesgo está caracterizado por el hecho de que, no obstante, la posibilidad de consecuencias negativas conviene, de cualquier modo, decidir mejor de una manera que de otra. Por lo tanto, indica, el riesgo depende de la atribución de los daños (posibles afectivamente decididos) debido a una resolución que se toma en el sistema, mientras que peligro se entiende como una posibilidad de daño digna de atención se habla de riesgo solo en el caso en que el daño se hace posible como consecuencia de una decisión tomada en el sistema y que no puede acontecer sin que hubiera mediado tal decisión. (Corsi, 1996, pp. 143-144)

Por otra parte, Guevara Ramírez (2012) lo califica en el orden laboral “como la posibilidad de que un trabajador sufra un determinado daño derivado del trabajo o cualquier elemento del trabajo con potencialidad de causar un daño” (p. 12). 
El trabajo incide en la salud de diversas formas, bien porque existen factores de riesgos que pueden afectar directamente y de forma negativa a la salud, o bien porque el propio trabajo lleva aparejado un desgaste físico o psíquico que incrementa las posibilidades de desarrollar determinada patología o enfermedad.

A tono con lo expresado en párrafos anteriores, resalta el papel fundamental de la prevención de los riesgos laborales en la búsqueda de la tutela o garantía de la seguridad y salud en el trabajo a través de técnicas eminentemente preventivas, realzándose esta faceta frente a la reparadora o resarcitoria que, aunque debe existir, ha de quedar relegada a un segundo lugar, para aquellos supuestos, que debieran ser cada vez menos frecuentes, en los que al no haberse logrado la eliminación total del riesgo se hayan ocasionado daños a los trabajadores y en última instancia la utilización del Derecho penal.

Es preciso afirmar que en la relación laboral, los riesgos a los que vienen expuestos los derechos de la persona del trabajador son mucho más frecuentes e intensos y ellos impone la necesidad de desplegar una tutela específica, sometida a normas propias, mucho más incisiva y permanente, que va a aparecer vinculada al propio contrato de trabajo y al desarrollo de la prestación laboral construyéndose así todo un sistema de actuación en la entidad encaminada a evitar o disminuir tales riesgos, de modo que no afecten a la salud ni a la seguridad de los trabajadores. Para ello es necesario hacer uso de mecanismos de control prima facie, mecanismos que se hacen necesarios dilucidar en el contexto cubano y su imbricación en la responsabilidad en el orden laboral, cuestión que será tratada en otro epígrafe.

\section{Los riesgos psicosociales: ¿accidente de trabajo o enfermedad profesional?}

Si bien en el anterior acápite quedó sustentado a la vinculación entre los riesgos y la seguridad y salud en el trabajo. Es válido adentrarse ahora en la tipificación de los riesgos y en específico acerca de los riesgos psicosociales que son tan controversiales en su comprensión.

De tal forma que los riesgos psicosociales ${ }^{17}$ "en nuestra vida diaria han tomado relevancia por dos aspectos fundamentales: uno, por su frecuencia de ocurrencia y el

17 Autores que han abordado el tema: Gemma Fabregat Monfort, Carlos Luis Alfonso Mellado, Carmen Salcedo Beltrán, Ana Mejías García, Miguel Ángel Gimeno Navarro, Jaime Alemañ Cano, 
otro por el impacto que tienen en la salud de las personas, aunque no se descarta el impacto que pueden tener en la gestión de una organización” (Melo Crespo, 2015, p. 208). Riesgos que estuvieron por varios años olvidados, asumiendo un papel de carácter secundario, pues las normas laborales y el entorno laboral consideraban solamente como riesgos los mecánicos, físicos, químicos y biológicos.

Sin embargo, a pesar de la evolución de la sociedad que trajo consigo cambios en los sistemas de producción, aún hay cierta intransigencia en reconocer diversas manifestaciones de los denominados riesgos profesionales emergentes -en el que se incluye en ella los riesgos psicosociales- en el concepto de accidentes de trabajo. Cuestión contradictoria pues hoy en día los accidentes por traumatismo han disminuido y sí han aumentado los accidentes y enfermedades del trabajo generadas por la exposición a riesgos ergonómicos y psicosociales.

La extensión y, en cierta medida, consolidación de los mecanismos de prevención de riesgos laborales han procedido a incorporar nuevos conceptos como cultura de la seguridad, riesgos psicosociales, ergonomía y violencia en el lugar de trabajo, que permiten afrontar nuevas situaciones que, si bien han sido siempre predicables de las relaciones laborales, hoy aparecen de forma especialmente virulenta por su frecuencia y su incidencia en la salud de los trabajadores. (Sánchez Pérez, 2016, p. 1)

No obstante, resulta patente que han de ser objeto también de análisis, evaluación y evitación los factores de tipo social o psicológico que pueden afectar, sea de forma orgánica o psicosocial, la salud de los trabajadores. Y ello porque puede constatarse cómo, en especial en determinados sectores y actividades, asistimos a una reducción significativa de los riesgos de tipo "tradicional”, si se nos permite la expresión, y a una creciente importancia de los de origen psicosocial. (Igartua Miró, 2011, p. 30)

La Organización Internacional del Trabajo (oIT, 2016) definió los factores de riesgo psicosocial (peligros psicosociales) en el año 1984, en términos de:

Las interacciones entre el medio ambiente de trabajo, el contenido del trabajo, las condiciones de organización y las capacidades, las necesidades y la cultura del

Fernando Ballester Laguna, Juan Ramón Rivera Sánchez, Nancy Sirvent Hernández y Enrique José Carbonell Vayá. 
trabajador, las consideraciones personales externas al trabajo que pueden - en función de las percepciones y la experiencia - tener influencia en la salud, el rendimiento en el trabajo y la satisfacción laboral.

Por lo que ejemplos de factores de riesgos psicosociales pudieran derivarse de dos vertientes ${ }^{18}$; una dentro del contenido del trabajo y otra del contexto laboral. La primera hace referencia al medio ambiente y equipo de trabajo, diseño de las tareas, carga, ritmo laboral y horario de trabajo. Y la segunda está dirigida a la función y cultura organizativa, papel en la organización, desarrollo profesional, autonomía en la toma de decisiones, control, relaciones interpersonales en el trabajo e interrelación hogar-trabajo.

A menudo los factores de riesgos psicosociales en el trabajo actúan durante largos períodos de tiempo, de forma continua o discontinua y son numerosos, de diferente naturaleza y complejos, dado que no sólo están conformados por diversas variables del entorno laboral, sino que, además, intervienen las actitudes, las motivaciones, percepciones, experiencias, la formación, la capacidad y los recursos personales y profesionales del trabajador. La personalidad y la situación vital del trabajador influyen tanto en la percepción como en la respuesta ante las distintas situaciones laborales. Es por ello, que ante cualquier problema de índole laboral no todos los trabajadores lo afrontan del mismo modo, ya que las características propias de cada trabajador determinan la magnitud y naturaleza de sus reacciones y de las consecuencias que sufrirá.

Por tanto, todo aspecto de la concepción, organización y gestión del trabajo así como de su contexto social y ambiental que tiene la potencialidad de causar daños físicos, sociales o psicológicos en los trabajadores ${ }^{19}$. Es por ello que a diferencia de los riesgos llamados "tradicionales", no exista la posibilidad de establecer una lista exhaustiva de los riesgos psicosociales y por ende se hable de una multicausalidad abierta, nacida de las inadecuadas condiciones de trabajo, las que favorecen los riesgos psicosociales y aparecen alteraciones que podemos encuadrar en estrés

18 NA: Encontrándose a tono con lo expuesto por la Organización Internacional del Trabajo en sus directrices y recomendaciones.

19 NA: Como bien se ha argumentado los riesgos psicosociales se derivan de las deficiencias en el diseño, la organización y la gestión del trabajo, así como de un escaso contexto social del trabajo, y pueden producir resultados psicológicos, físicos y sociales negativos, como el estrés laboral, el agotamiento o la depresión. 
laboral, acoso laboral (mobbing) y sexual, el síndrome de estar quemado por el trabajo (burnout), la violencia en el trabajo que a la vez son tipos de riesgos psicosociales. (Unión General de Trabajadores [ugT], 2016)

Realmente, estamos ante riesgos y patologías que tienen una larga trayectoria de estudio e investigación en el campo de la medicina y la psicología y que, paulatinamente, ha ido desembarcando en el ámbito jurídico. No obstante lo anterior, a todos ellos cabría aplicar, aunque no sin dificultades, los mecanismos de tutela que a los riesgos profesionales brinda el ordenamiento jurídico. (Igartua Miró, 2011, p. 32)

En este tipo de riesgos se utilizan muchas técnicas de prevención con el objetivo de mitigar el riesgo.

Sin embargo, al hacer uso de las técnicas de prevención, antes ha de utilizarse una evaluación del riesgo, como núcleo duro de cualquier sistema preventivo, cuya evaluación supone entonces un proceso de consolidación de la información tomada a través del análisis de los factores de riesgo, de los resultados de los indicadores de riesgo (accidentes, enfermedades, resultados de los cuestionarios de factores de riesgos psicosociales, entre otros) y de la aplicación de los criterios de evaluación específicos. (Mansilla Izquierdo, 2012, p. 30)

Donde irán a descansar en medidas distintas a las empleadas en relación a otros agentes y riesgos. Es preciso señalar que muchas veces el ámbito de actuación resulta complicado pues se analiza las relaciones sociales dentro de la organización productiva.

Por lo que la utilización de otros instrumentos preventivos como la información y la formación específica del trabajador permitirá brindarle un resultado más concreto, al mismo tiempo no estaría de más una intervención legislativa que incluyera tanto la definición jurídica de estas dolencias como los mecanismos de prevención y tutela a adoptar por el empleador en el marco de su política de prevención de riesgos laborales.

No obstante esta precisa ampliación, no debe ignorarse que la prevención no viene referida a todo tipo de riesgo sino que aparece centrada en los relacionados con la prestación de servicios desempeñada, en la medida en que el concepto de seguridad 
y salud en el trabajo, no señala el contenido absoluto de un determinado bien sino que pone en relación éste con determinados ataques al mismo. (Igartua Miró, 2011, p. 35)

Resulta actual "el tema de los riesgos psicosociales en pos de determinar su inclusión o no como enfermedad profesional lo que se deriva de ello"20 (Agra Viforcos, 2011, p.29), claro está que "su principal obstáculo se encuentra en el origen de ella en lo que la jurisprudencia ha denominado como la "teoría de la multicausalidad" (Sánchez Pérez, 2016, p. 88) y que se encuentra más apegada a la doctrina médica ya que admite la concurrencia de una causalidad múltiple en la mayoría de las enfermedades.

En la lista de enfermedades profesionales de la oIT, en su última revisión (oIT, 2010), deja por sentado como recomendación, la elaboración de una lista nacional - a los países miembros- de enfermedades profesionales previa consulta con las organizaciones de empleadores y de trabajadores más representativas; debiendo incluir entre otras enfermedades las que se recogen en el Anexo de dicha recomendación, e incluir en la medida de lo posible, una parte titulada "presuntas enfermedades profesionales".

Lo curioso de lo planteado se encuentra en que por primera vez se han incluido de manera específica en la lista los trastornos mentales y del comportamiento, dejando entreabiertos puntos que permitirán el reconocimiento del origen profesional de enfermedades que no figuran en la lista siempre y cuando se haya establecido un vínculo entre la exposición a los factores de riesgo que resulte de la actividad laboral y las enfermedades contraídas por el trabajador.

No cabe la menor duda que, en el ámbito laboral actual, afrontar con éxito los riesgos psicosociales en el lugar de trabajo es fundamental para proteger la salud y la seguridad de los trabajadores trayendo consigo el aumento de la productividad. (Quesada Segura, 2015, pp. 220 y ss; González-Posada Martínez, 1997, pp. 17 y ss)

De ahí que la oit (2016):

Promueva la armonización de las listas nacionales de enfermedades profesionales proporcionando asistencia adicional sobre la base de la lista de enfermedades profesionales del organismo, apoyando la integración de los riesgos psicosociales en la

20 NA: Precisamente Agra Viforcos deja claro las principales diferencias entre enfermedad profesional $\mathrm{y}$ accidente de trabajo. 
evaluación y gestión de riesgos y en los sistemas de gestión y su vinculación con las sustentabilidad de las intervenciones.

Lo que conllevaría a que se permitiera eventualmente, la calificación de aquellas enfermedades cuyo nexo de causalidad con el trabajo quedara acreditado en sede judicial o bien administrativa, teniendo una adecuada calificación como enfermedades profesionales y no como accidente de trabajo.

La criticable exclusión de las enfermedades psicosociales del campo de regulación de las enfermedades profesionales implica, entre otras cosas, negar la propia identidad y naturaleza de tales patologías. Resulta incomprensible y falsa la reconducción que se realiza hacia los accidentes de trabajo, pues la tendencia está en superar la disfunción que hoy en día propicia el legislador nacional al derivar patologías que indiscutiblemente tienen la naturaleza de enfermedad profesional hacia el terreno del accidente de trabajo. (Maldonado Molina y Villar Cañada, 2010, pp. 197-202)

Por todo lo anteriormente expresado, es evidente la interrelación de la seguridad y salud y el riesgo en el ámbito laboral. Siendo el núcleo esencial para que el empleador diseñe un sistema de gestión encaminado a la salvaguarda del trabajador. No obstante, debe precisarse el amplio espectro que contiene en sí los riesgos; desde los tradicionales hasta los riesgos psicosociales que hoy en día son más habituales en el entorno laboral. Y, por ende, la necesidad del reconocimiento como enfermedad del trabajo y su inclusión como enfermedad profesional. Teniendo claro esas cuestiones en preciso adentrarse en los mecanismos de control y responsabilidad en los hace suyo el Derecho laboral cubano y pone en práctica como elementos que pueden jugar un papel fundamental en la prevención de la seguridad y la salud en el trabajo.

\section{Mecanismos de control y responsabilidad en el orden laboral en Cuba}

La Constitución de la República de Cuba en su artículo 49 presenta uno de los preceptos básicos en la configuración del modelo socioeconómico cubano, al garantizarse por parte del Estado al trabajador el derecho a la protección, seguridad e higiene del trabajo, mediante la adopción de medidas adecuadas para la prevención de accidentes y enfermedades profesionales. Lo que denota una manifestación 
concreta del derecho a la vida y a la salud de los ciudadanos ante el riesgo acentuado que supone la prestación de trabajo. (Constitución de la República de Cuba, 1976, art. 49)

El vigente Código de Trabajo cubano, define en su artículo 2 inciso g) como principio fundamental al Derecho de Trabajo, "el derecho de los trabajadores a la seguridad y salud en el trabajo, mediante la adopción de medidas para la prevención de accidentes de trabajo y enfermedades profesionales" (Ley N. o 116, 2013, art. 2, inciso g). De lo cual mantiene el mismo interés que la Carta Magna en busca de la "cultura de la prevención" aunque cabe destacar la incongruencia que existe en la denominación siendo más atinado el uso de la seguridad y salud en el trabajo pues su contenido es más abarcador según lo planteado en anteriores ideas y se encuentra a tono a lo dispuesto en el Convenio N. ${ }^{\circ} 155$ de la ort.

De tal forma que el derecho de los trabajadores a la seguridad y salud en el trabajo constituye un derecho subjetivo de origen contractual y de estricta creación y configuración legal, sin que estos rasgos caracterizadores del derecho entren en contradicción entre sí.

Constituye un derecho subjetivo de origen contractual porque nace de la "formalización de la relación laboral entre el empleador y el trabajador y de su propio contenido" (Ley N. ${ }^{\circ} 116,2013$, art. 20 y 24). En cuanto a la creación legal se debe al reconocimiento expreso en favor de los trabajadores a través de normas de rango legal (Huertas, 2018). Por último, será de configuración legal a causa de su régimen jurídico el cual se encuentra desarrollado en normas legales y reglamentos según sea el caso, pudiendo desarrollarse a través de los "convenios colectivos de trabajo" (Ley N. ${ }^{\circ} 116,2013$, art. 181).

Precisamente como parte del reconocimiento al señalado derecho y su protección en aras de una cultura preventiva, nace en la figura del empleador, la deuda de seguridad, siendo reconocida en el Convenio N. ${ }^{\circ} 155$ de la oit, aunque, haciendo uso del término de lo que es "factible y razonable" (оiт, 1981) para dar un margen de flexibilidad al empresario en cuanto a la exigencia de dichos deberes empresariales a la luz del principio clásico de exoneración de responsabilidad: ad imposibilia nemo tenetur21, adoptando todas las medidas necesarias e incorporando a su dinámica

21 "Nadie está obligado a realizar lo imposible, porque si el acto condicionado fuese físicamente irrealizable (imposibilidad física) o legalmente prohibido (imposibilidad jurídica), produciría según los casos la invalidez de la condición, subsistiendo la obligación principal" (Cisneros Farías, 2003, p. 12). 
empresarial la cultura de la seguridad, rechazando los comportamientos contrarios a estos principios.

Es la deuda de seguridad y salud quien grava al empleador frente a sus trabajadores, pero también frente a los poderes públicos, de acuerdo con lo que se regula y se garantice, controlándose su cumplimiento. De ahí "su doble naturaleza jurídica en lo privado y en lo público” (Montoya Melgar y Pizá Granados, 2000, p. 72). Esta ambigüedad se dimensiona en el sentido en que el empleador debe seguridad a sus trabajadores, como una más de las obligaciones que tienen que ser incorporadas per se al contenido del contrato de trabajo y a la vez viene obligado a cumplir directamente las normas promulgadas o reconocidas por dicho poder en materia de seguridad y salud laboral y objeto luego de la incorporación automática al contenido del contrato de trabajo.

Efectivamente, "la doble naturaleza de los deberes de seguridad y salud en el trabajo explica teórica y prácticamente la existencia de un doble canal protector público y privado de la seguridad y salud en el trabajo" (Gutiérrez-Solar Calvo, 1999, pp. 77-168). Razón por la cual "trasciende en el ámbito laboral y se dirige hacia lo penal” (Baylos Grau y Terradillos Basoco, 1997, pp. 103-110), tipificando el Estado una serie de infracciones administrativas, laborales y de delitos para sancionar de acuerdo a su naturaleza más allá de otras consecuencias, cuando se transgrede las normas de seguridad y salud en el trabajo.

El actual Código de Trabajo establece una serie de obligaciones concretas que desarrollan el deber general de protección del empleador y que "dimensiona en garantizar una protección eficaz entorno a la seguridad y salud de los trabajadores en todos los aspectos relacionados con el trabajo" (Ley N. ${ }^{116}$, 2013, arts. 134, 135, 137 y 139). Ahora bien, a partir del conjunto de deberes generales y específicos que posee el empleador respecto a la prevención y protección de los riesgos laborales, deviene el uso de mecanismos de control, que se articula en garantizar el cumplimiento de tales deberes. Estos mecanismos pudieran ser de carácter colectivo o administrativos, a los efectos de la legislación cubana queda en manos del ámbito administrativo. Digo esto a razón de que el Decreto N.o 326, "Reglamento del Código de Trabajo", derogó la Resolución N. 39 de fecha veintinueve de junio de dos mil siete, emitido por el Ministerio de Trabajo y Seguridad Social, "Bases Generales de la Protección, Seguridad e Higiene del Trabajo" en la que su artículo 24 obligaba a la constitución de un Comité de Seguridad y Salud en el Trabajo, de lo que hoy adolece las diversas entidades laborales y que coadyuvaba en la labor 
de vigilancia y control del cumplimiento de la normativa en materia de salud laboral y de condiciones en que se desarrolla el trabajo.

En cuanto al mecanismo administrativo, "se sostiene a través del artículo 49 de la Carta Magna el interés del Estado de tutelar el referido derecho, concretándose en la ejecución de varias funciones"22 (Viamontes Guilbeaux, 2007, p. 370) entre las que se señalan: la de fiscalización, asesoría, información, requerimiento, exigencia de responsabilidad y aplicación de medidas sancionadoras. Es el Ministerio de Trabajo y Seguridad Social la encargada de proponer, dirigir y controlar la política del Estado y el Gobierno en materia de trabajo y seguridad social (Ley N.o 116, 2013, art. 188), por lo que la vigilancia y el control del cumplimiento de la normativa sobre seguridad y salud en el trabajo se desplaza a través de la Oficina Nacional de Inspección del Trabajo, como entidad adscrita e independiente al Ministerio de Trabajo y Seguridad Social (Ley N. o 116, 2013, art. 192), de igual manera el Estado cubano facultó a otros organismos y empleadores de acuerdo a su competencia la inspección del trabajo (Ley N.o 116, 2013, art. 191).

El artículo 223 del Reglamento del Código de Trabajo dispone que cuando de los hechos considerados como infracciones pueda derivarse la exigencia de responsabilidad penal, el inspector lo informa a la autoridad que ordenó la inspección, a los fines de formular la denuncia ante la autoridad correspondiente. Sin embargo, no existe un referente obligado en la interpretación de cuáles serían las conductas graves o muy graves en que debería actuar el Derecho penal máxime cuando el artículo 296 del Código Penal vigente constituye un delito de resultado, por tanto, todas las infracciones recogidas el artículo 228 del mencionado reglamento pudieran ser de interés penal. Es preciso señalar que el legislador no contempló como infracciones administrativas y laborales a la seguridad y la salud en el trabajo, los riesgos que pudieran derivarse de lo psicosocial, quedando en terreno de nadie y bien pudiera analizarse desde el contexto del Derecho laboral o penal, según la trascendencia.

Vale señalar la introducción al reglamento del término accidentes mortales, que como bien plantea el artículo 232, la Inspección del Trabajo solicita el inicio de un proceso penal a los presuntos responsables de accidentes mortales, lo que deja sin efectos el artículo 296 apartado 2 y 4 del Código Penal vigente los que se

22 NA: Atendiendo al Proyecto constitucional que se encuentra en discusión y consulta en Cuba, vale señalar que existe la propuesta indicada en el artículo 80 el cual mantiene la protección a la seguridad y la salud en el trabajo, la diferencia entre el presente artículo 49 de la Carta Magna y el proyecto ha sido el cambio de términos. (Asamblea Nacional del Poder Popular [ANPP], 2018). 
refieren a las lesiones laborales, por tanto, quedará solo en el ámbito administrativolaboral, tal accidente. Dejando claro lo anteriormente analizado, cabe adentrarnos en determinadas problemáticas que atañan al Derecho penal en Cuba respecto a la seguridad y salud de los trabajadores.

\section{Los delitos contra la seguridad y la salud de los trabajadores: lo que sobra y lo que falta en Cuba}

Parte de la autoría del nombre de este epígrafe viene de la mano de uno de los primeros estudiosos del tema, Lascuraín Sánchez (2004), quien en una publicación retrató lo que acontecía en España acerca de los delitos contra los derechos de los trabajadores y es a través de estas palabras que igual propósito se pretende lograr.

\section{Título X}

Delitos contra los derechos laborales

\section{Capítulo I}

Incumplimiento de normas de protección e higiene del trabajo

Artículo 296. 1. El responsable directo de la aplicación o ejecución de las medidas referentes a la protección e higiene del trabajo que, a consecuencia de infringir, dentro del ámbito de su competencia, las disposiciones establecidas al respecto, dé lugar a que se produzca la muerte de algún trabajador, incurre en sanción de privación de libertad de dos a cinco años.

2. Si, como consecuencia de la infracción a que se refiere el apartado anterior, se producen lesiones graves o graves perjuicios para la salud a algún trabajador, la sanción es de seis meses a dos años o multa de doscientas a quinientas cuotas.

3. El que, por no haber ordenado, teniendo la obligación de hacerlo, las medidas de protección e higiene del trabajo a quienes deban cumplirlas, dé lugar a que se produzca la muerte de un trabajador, incurre en sanción de privación de libertad de uno a tres años o multa de trescientas a mil cuotas.

4. Si, como consecuencia de la infracción a que se refiere el apartado anterior, se producen lesiones graves o graves perjuicios para la salud a algún trabajador, la sanción es de tres meses a un año o multa de cien a trescientas cuotas. (Rivero García y Bertot Yero, 2017, pp. 206-207) 
En la actualidad y según los datos estadísticos aportados por la Oficina Nacional de Estadísticas e Información de la República de Cuba (oneI, 2018), en Cuba el año 2017 arrojó la suma de 3228 accidentes de trabajo, de ellos 87 fallecidos y lesionados por accidentes de trabajo 3284 trabajadores. Denotándose que a pesar de existir una legislación laboral actual aún persisten los graves accidentes y lamentables consecuencias que trasciende al ámbito familiar. Por tal motivo hoy se nos presenta un artículo del Código Penal vigente, con poca trascendencia y el cual no se corresponde con la nueva realidad que existe. El delito de incumplimiento de normas de protección e higiene del trabajo, registrado en el artículo 296 presenta como objeto de protección los derechos laborales, pero especialmente se enfoca en la vida de los trabajadores a criterio de Larramendi Domínguez (2003), constituyendo un delito por imprudencia (pudiendo ser culpa consciente o inconsciente) y de resultado pues tiene que existir daños, la muerte o las lesiones de algún trabajador (p. 110).

La problemática que nos encontramos en la configuración del tipo penal parte de la incongruencia que existe entre lo que expresa la Constitución de la República y el vigente Código de Trabajo cubano en relación con el Código Penal y como bien se explicó en párrafos anteriores resulta más abarcador el uso de seguridad y salud en el trabajo por encontrarse en sintonía con lo dispuesto en el Convenio N. 155 de la oit.

En este momento, sucede; que existe un cambio de contenido en el bien jurídico a proteger, pues es la vida y la salud de los trabajadores y por supuesto la integridad física ${ }^{23}$ y no como se venía sosteniendo, dejando a un lado a la salud y a la integridad física. Es cierto que existe un importante sector doctrinal que arguyen como bien jurídico la seguridad y salud en el trabajo, hay que entender que esa seguridad es el marco condicionante de la eficacia en la protección de la vida o salud. Pero no es el auténtico bien jurídico (Baylos Grau y Terradillos Basoco, 1997, p. 116). Sin embargo, la construcción del delito narrado al ser de resultado cabe la posibilidad de pensarse como bien jurídico el de seguridad y salud en el trabajo, en este caso sería lesiva para esas condiciones de seguridad. Por cuanto exigir la lesión sería entrometerse en ámbitos propios de los delitos tradicionales contra la vida y la integridad corporal recogidos en el título viı del Código Penal cubano.

23 NA: Precisamente el artículo 146, perteneciente al título de disciplina laboral del propio Código de Trabajo obliga al empleador a la protección a la integridad física, psicológica y a la dignidad de los mismos, o sea, de los trabajadores. 
Entretanto, asumo que la construcción del tipo penal deberá castigar la infracción de la normativa laboral por su exigencia, teniendo como base una determinada proyección del comportamiento infraccional al mundo exterior (Terradillos Basoco y Boza Martínez, 2017, p. 126), constituyendo la transgresión como requisito típico del modo de lesionar el pretendido bien jurídico.

Se considera que la vida y la salud tendrán que tutelarse en el título X como derechos laborales, bienes jurídicos colectivos. Al contrario, de regularse en el Código Penal de forma individual, existirían escasos argumentos para su tratamiento independiente en defensa de los trabajadores y por ende, colisionaría con los artículos 261, 272, 273 y 274 en relación con el artículo 48 todos del Código Penal vigente.

\begin{abstract}
Derechos colectivos, pues, que no pueden tener rango inferior al de los derechos individuales. La dimensión colectiva no les resta valor; por el contrario, en el marco del Estado social, les añade jerarquía. Esta consideración, obvia por otra parte, está en la base de la legitimidad de la tutela penal de los derechos de los trabajadores: son derechos que no pierden relevancia por el hecho de tener naturaleza colectiva, ni se degradan cuando sus titulares traspasan las puertas de los establecimientos en que trabajan. (Terradillos Basoco y Boza Martínez, 2017, p. 127)
\end{abstract}

En este sentido, resalta la necesidad de una tutela jurídica efectiva que proteja los intereses de los trabajadores entorno a la seguridad y salud, no es solo en el ámbito del Derecho laboral y administrativo, deberá imbricarse la tutela penal, para dar cumplimiento al artículo 49 de la Constitución de la República de Cuba.

La indefectibilidad de la intervención penal en la seguridad y salud se encuentra ligada a la relevancia del bien jurídico propuesto el cual requiere una protección distinta a los delitos de homicidio y lesiones con un resultado imprudente descrito en la lex penal cubana. Cierto es, que, antes de imponer una sanción penal, deberá accionar la sanción laboral, lo cual esta opción no consigue niveles de motivación necesarios para que el empleador, según dispone la Ley laboral y su reglamento, cumpla con lo establecido en materia de prevención, ya que las medidas que normalmente son usadas se encuentran en la obligación de hacer la clausura, la paralización y la multa (Decreto N. o 326, 2014, art. 231), aun así se necesita el uso de otras sanciones como las penas privativas de libertad, exclusivas del Derecho penal para poder conseguir la motivación del empleador. 
"La intervención penal podrá asumir diferentes formas que determinan modelos jurídicos de distinta configuración y extensión del Derecho penal, en los cuales tienen que verse diferentes factores que van desde el grado de utilización de otros mecanismos sancionadores extrapenales" (Hortal Ibarra, 2009, pp. 86-87); hasta la forma de articular las soluciones destinadas a compensar la desigualdad de fuerzas existentes en el conflicto trabajador-empleador (Gallo, 2017). Ya sea a través de la autorregulación ${ }^{24} \mathrm{y}$ de la intervención de la Administración por medio de sistemas de inspección.

Estas formas de intervención penal en materia de seguridad y salud en el trabajo se enfoca en dos formas: la incorporación a las figuras que tipifican los delitos de homicidio y de lesiones de carácter imprudentes una causa de agravación cuyo resultado de muerte o lesiones se produzca como consecuencia de la infracción de normas de seguridad y salud en el trabajo, y la segunda la creación de un delito de peligro, como mecanismo de adelantamiento de las barreras de protección en la que consiste en reprimir la conducta grave ante el incumplimiento de las normas preventivas, sin llegar a que el actuar conduzca o no a la muerte o lesiones de un trabajador.

Estimo que incluir una causa de agravación no resolvería tal problema pues sería contra producente a la cultura de la prevención que se propugna pues solo se podría lograr si se dirige contra la conducta consciente del sujeto.

Cabe señalar que el problema de los accidentes de trabajo no consiste en que haya sujetos que quieran causarlos, sino en que quienes son responsables de la realización del trabajo, no aplican en ello el cuidado necesario, incumpliendo las medidas de prevención. (Gallo, 2017, pp. 245-246)

Por otro lado, aparecen los controversiales delitos de peligro concreto ${ }^{25}$, los cuales tipifican el riesgo que se ha podido delimitar la norma de cuidado. Por lo que

$24 \quad$ El mecanismo de autorregulación proviene del campo del Derecho privado, habiéndose extendido hacia el Derecho público mediante las referencias legales al estado de la técnica o las remisiones legales y reglamentarias a normas técnicas. Se producen, así, conexiones, cada vez más frecuentes, entre el ordenamiento jurídico general y los resultados de la autorregulación generados en los subsistemas técnicos (normas técnicas, remisiones al estado de la técnica), en los subsistemas éticos (integración de conceptos derivados de la autorreflexión ética) o en los subsistemas profesionales y las empresas (referencias normativas a la lex artiso a las buenas prácticas). (Darnaculleta i Gardella, 2005 , pp. 71 y ss)

25 NA: La doctrina recrea un concepto de delitos de peligro concreto definiéndolo como aquellos que requieren que la acción del sujeto activo cause un resultado consistente en la creación de un riesgo 
la creación del peligro dependerá de una norma de actuación definida al principio, pudiendo sancionar penalmente a quien la incumple y crea un peligro, no así en el caso de la imprudencia en el que debe verificarse la existencia de una determinada lesión.

Es en ese preciso momento que entra a jugar un papel fundamental el uso de la técnica legislativa de las normas penales en blanco, como dador de seguridad jurídica en un escenario en el que es necesario, teniendo mayor efecto preventivo y una aplicación más constante.

Desde esta óptica, la protección a la vida, integridad física y la salud de los trabajadores se afectará en el instante en que la actividad laboral se desarrolle sin las condiciones que garanticen un trabajo seguro, no siendo necesario la producción del peligro concreto hacia un trabajador como individuo. El tema acerca de los delitos de peligro resulta escabroso pues es asociado con la expansión del Derecho penal. A lo que muy sabiamente respondió Lascuraín Sánchez (2005) al manifestar que:

El problema no es que el Derecho penal se expanda, se reduzca o se transforme, lo cual parece inevitable si quiere responder a los cambios en las necesidades y en las estructuras sociales, sino, en cada caso, si está justificada la expansión, la reducción o la transformación. (p. 6)

\section{Consideraciones finales}

Interrogantes quedan en el camino pues, resulta insuficiente abarcar en un artículo todo lo relativo a la intervención penal en el ámbito de la seguridad y la salud en el trabajo, queda mucho desde la óptica cubana trabajar en pos de perfeccionar nuestras leyes y su interpretación.

Una vez analizado lo relativo a los elementos estructurales de la seguridad y la salud en el trabajo, su imbricación con el riesgo, la existencia de mecanismos de control y la responsabilidad en el orden laboral, hasta determinar en pocos espacios lo que sobra o falta en los delitos contra la seguridad y salud de los trabajadores;

determinado de lesión para el interés protegido. Es decir, en unas condiciones en las que se pueda afirmar que el bien jurídico se encontraba en una situación próxima a la lesión. Siendo, por tanto, delitos de resultado en los que el juez debe valorar si la conducta del sujeto activo puso o no el peligro efectivo la vida, salud o integridad física del trabajador. 
queda claro que lo estipulado en el artículo 296 del Código Penal vigente se encuentra en una realidad de la que hoy no impera en Cuba, necesitada de un vuelco suficientemente capaz de atemperarse a lo vivido en la actualidad, ¿el qué pretendemos? y ¿cómo lo resolvemos? Son interrogantes por esclarecer para fortalecer la función penal en favor de la vida, la integridad física y la salud de los trabajadores que son en definitivas el núcleo fundamental de la seguridad y salud en el trabajo que como objeto de protección se hace necesario retomar para su efectiva revisión.

Es esencial para una correcta comprensión del cual debería ser la respuesta del Derecho penal en los ámbitos en los que ocupa una posición que es, al mismo tiempo, subsidiaria y prevalente respecto de otros ámbitos del ordenamiento jurídico. Solo a partir del conocimiento de esas otras áreas de conocimiento podemos concretar la finalidad que se debe perseguir con la intervención del Derecho penal, siendo este el único procedimiento válido para legislar de forma justa, proporcionada, eficiente y eficaz (Corcoy Bidasolo, 2005, p. 18). Y es lo que se pretende realizar.

\section{Referencias}

Arroyo Zapatero, L. (1996). Derecho y Riesgo. En L. Arroyo Zapatero (Ed.), Riesgo y trabajo: legislación y formación en seguridad. Responsabilidades (pp. 1-14). Madrid, España: Editorial Mapfre, S.A.

Asamblea Nacional del Poder Popular. (2018). Proyecto de Constitución de la República de Cuba. La Habana, Cuba: Empresa de Artes Gráficas Federico Engels.

Bayo Mayor, J. (mayo de 2017). El trabajo y los trabajadores, Revista Palabra Nueva, (270), p. 44.

Baylos Grau, A. y Terradillos Basoco, J. (1997). Derecho Penal del Trabajo (2 ed. Rev.). Madrid, España: Editorial Trotta.

Beck, U. (2002). La sociedad del riesgo global. Madrid, España: Siglo veintiuno de España editores, S.A.

Bosch Taquechel, L. (14 de febrero de 2017). ¿Y usted se siente seguro? Periódico Juventud Rebelde, p. 7.

Cabanellas, G. (1949). Tratado de Derecho Laboral (Tomo 1). Buenos Aires, Argentina: Ediciones El Gráfico Impresores. 
Callizo, M. del P. (2014). Prevención de riesgos laborales. Principales Consideraciones. Estudio Jurídico Gross Brown. Recuperado de http://iaba.org/site/DOCTRINA_JURIDICA/ derecho_trabajo/Prevencion_Riesgos_Laborales.pdf.

Cisneros Farías, G. (2003). Diccionario de frases y aforismos latinos: una compilación sencilla de términos jurídicos. México D.F., México: Universidad Nacional Autónoma de México.

Código del Trabajo de Chile. (2002). Recuperado de http://www.dt.gob.cl/m/1620/articles-95516_recurso_1.pdf.

Código Sustantivo del Trabajo de Colombia. (1950). Recuperado de http://copaso.upbbga. edu.co/legislacion/Codigo\%20Sustantivo\%20del\%20trabajo.pdf.

Código de Trabajo de Costa Rica. (1943). Recuperado de http://www.cendeisss.sa.cr/etica/ codtrabajo.pdf.

Código del Trabajo de Ecuador. (2005). Recuperado de http://www.trabajo.gob.ec/wpcontent/uploads/2015/03/CODIGO-DEL-TRABAJO-1.pdf.

Código de Trabajo de El Salvador. (1972). Recuperado de http://www.asamblea.gob.sv/ eparlamento/indice-legislativo/buscador-de-documentos-legislativos/codigo-de-trabajo.

Código de Trabajo de Guatemala. (1961). Recuperado de http://www.asomet.org/wpcontent/uploads/2016/06/C\%C3\%B3digo-de-Trabajo.pdf.

Código del Trabajo y sus reformas de Honduras. (1959). Recuperado de http://portalunico.iaip.gob.hn/Archivos/SecretariadeTrabajo/Regulaciones\%28normativa\%29/ Leyes/2015/Codigo\%20de1\%20Trabajo\%20y\%20sus\%20Reformas.pdf.

Código del Trabajo de Nicaragua con sus reformas, adiciones e interpretación auténtica. (1996). Recuperado de http://www.poderjudicial.gob.ni/cjnejapa/image/ codigo-trabajo.pdf.

Código de Trabajo de Panamá. (1995). Recuperado de http://docs.panama.justia.com/ federales/codigos/codigo-de-trabajo.pdf.

Código de Trabajo de República Dominicana. (1992). Recuperado de http://www.sipi.siteal. org/sites/default/files/sipi_normativa/codigo_de_trabajo_republica_dominicana.pdf.

Compendio normativo en materia de Seguridad y Salud en el Trabajo del Uruguay. (s.a).Recuperado de https://www.mtss.gub.uy/c/document_library/ get_file?uuid=a44b975b-0e5d-4f3e-855b-e5bd05fad7b5\&groupId=11515.

Compendios de Códigos Penales. Recuperado de www.uo.edu.cu. 
Corcoy Bidasolo, M. (2005). Prólogo. En J. C. Hortal Ibarra, Protección penal de la seguridad en el trabajo (pp. 18-20). Barcelona, España: Atelier.

Corsi, G., Esposito, E. y Baraldi, C. (1996). Glosario sobre la teoría social de Niklas Lubmann. Recuperado de https:/ceducativa.weebly.com/uploads/1/5/0/9/15091428/glosariosobre-teoria-social-de-luhmann.pdf.

Darnaculleta i Gardella, M. M. (2005). Autorregulación y Derecho Público: La Autorregulación regulada. Madrid, España: Marcial Pons.

Decreto N. 326. Gaceta Oficial de la República de Cuba, La Habana, Cuba, 17 de junio de 2014.

Franco González, J. (2015). Seguridad y salud en el trabajo y prevención de riesgos laborales: marco histórico-conceptual y análisis técnico-jurídico. En G. García González y A. Garrígues Giménez (Eds.), Manual de Derecho de la Prevención de Riesgos Laborales (pp. 19-40). Valencia, España: Tirant lo Blanch.

Gallo, P. (2017). Los riesgos penales laborales: Un análisis crítico sobre el artículo 316 del Código Penal español y una propuesta de tipo penal de peligro para el ordenamiento jurídico argentino (tesis doctoral), Universidad Autónoma de Madrid, Madrid, España.

González-Posada Martínez, E. (1997). La política de prevención de riesgos laborales, objetivos y agentes. Papel de las administraciones públicas. En M. E. Casas Baamonde, M. C. Palomeque López y F. Valdés Dal-Ré (Eds.), Seguridad y salud en el trabajo. El nuevo derecho de prevención de riesgos profesionales (pp. 17-34). Madrid, España: La Ley-Actualidad, S.A.

Gran Diccionario de la Lengua Española - Larousse. (1996). Edición Larousse Planeta S.A., Edición electrónica, s/l.

Guevara Ramírez, L. (2012). A propósito de los llamados factores de "riesgos emergentes" en el medio laboral (tesis de maestría). Universidad de la Habana, La Habana, Cuba.

Gutiérrez-Solar Calvo, B. (1999). El deber de seguridad y salud en el trabajo. Un estudio sobre su naturaleza jurídica. Madrid, España: Consejo económico y social.

Hortal Ibarra, J. C. (2004). Legitimación y eficacia de la intervención penal en el ámbito de la prevención de riesgos laborales. En S. Mir Puig y M. Corcoy Bidasolo (Eds.), La politica criminal en Europa (pp. 237-251). Barcelona, España: Atelier.

Hortal Ibarra, J. C. (2009). Concreción del riesgo típico en el delito contra la seguridad del trabajo (art. $316 \mathrm{cP}$ ). A la vez, un apunte sobre algunos modelos europeos de protección 
"penal" de la prevención de riesgos laborales. En S. Mir Puigy M. Corcoy Bidasolo

(Eds.), Protección penal de los derechos de los trabajadores (pp. 73-121). Buenos Aires, Argentina: Editorial Edisofer S. L.

Huertas Díaz, O. (2018). Principio de legalidad penal y justicia transicional en Colombia. Bogotá: Editorial Ibáñez.

Igartua Miró, M. T. (2011). Sistema de prevención de riesgos laborales (2 ed.). Madrid, España:

Editorial Tecnos.

Jasán Nieves, J. (12 de enero de 2015). Salvar la vida no es un lema. Periódico Trabajadores, p. 3.

Ley N. ${ }^{\circ} 116$. Gaceta Oficial de la República de Cuba, La Habana, Cuba, 17 de junio de 2014.

Ley Federal del Trabajo de México. (2015). Recuperado de http://www.diputados.gob.mx/ LeyesBiblio/pdf/125_120615.pdf.

Ley N.o 213, Código del Trabajo de Paraguay. (1993). Recuperado dehttp://humanidades. uni.edu.py/wp-content/uploads/2016/07/Ley-213-93-C\%C3\%B3digo-Laboral.pdf.

Ley N. ${ }^{4}$ 496, Modifica, amplía y deroga artículos de la Ley N.o 213/1993, Código de Trabajo de Paraguay. (1995). Recuperado de http://www.mtess.gov.py/index.php/ download_file/view_inline/536.

Ley General del Trabajo de Perú. (2006). Recuperado de http://www4.congreso.gob.pe/ comisiones/2006/trabajo/ley-general/texto.pdf.

Larramendi Domínguez, E. (2003). Delitos contra los Derechos Laborales. En M. Goite Pierre (Ed.), Derecho Penal Especial (Tomo 2) (pp. 355-366). La Habana, Cuba: Editorial Félix Varela.

Lascuraín Sánchez, J. A. (2004). Los delitos contra los derechos de los trabajadores: lo que sobra y lo que falta. Anuario de Derecho Penal y Ciencias Penales, (57), pp. 19-52.

Lascuraín Sánchez, J. A. (2005). La prevención penal de los riesgos laborales: cinco preguntas. En J. C. Carbonell Mateu, Estudios penales en homenaje al profesor Cobo del Rosal (pp. 1-32). Madrid, España: Editorial Dykinson. Recuperado de http://www.cienciaspenales.net/files/2016/10/3laprevencionpenaldelosriesgoslaborales-penal-economico. delitos-contra-trabajadores.pdf.

López Sánchez, A. (mayo de 2017). Del Trabajo que trabaja, Revista Palabra Nueva, (270), pp. 29-30. 
López Gandía, J. y Blasco Lahoz, J. F. (2004). Curso de prevención de riesgos laborales. Valencia, España: Tirant lo Blanch.

Luceño Moreno, L., Martín García, J., Rubio Valdehita, S. y Jaén Díaz, M. (2008). Psicología y riesgos laborales emergentes, los riesgos psicosociales. Revista de Psicología y psicopedagogía, 7(2), pp. 111-129. Recuperado de https://dialnet.unirioja.es/descarga/ articulo/2800121.pdf.

Maldonado Molina, J. A. y Villar Cañada, I. (2010, enero). Protección social y riesgos psicosociales: A propósito del nuevo listado de enfermedades profesionales del oit. Revista de Prevención de Riesgos Psicosociales y Bienestar en el Trabajo. Recuperado de https://www.juntadeandalucia.es/empleo/webiaprl/larpsico/sites/es.empleo.webiaprl. larpsico/files/recursos/revista_cientifica/RevistaLarpsico01.pdf.

Manguela Díaz, G. (11 de mayo de 2015). Disminuye accidentabilidad del trabajo. Periódico Trabajadores, p. 5.

Manguela Díaz, G. (24 de abril de 2017). Una pandemia que nos afecta a todos. Periódico Trabajadores, p. 5.

Mansilla Izquierdo, F. (2012). Manual de riesgos psicosociales en el trabajo: teoría y práctica. Recuperado de https://nidodisciplinapositivamendoza.files.wordpress.com/2013/05/ manual-riesgos-psicosociales.pdf.

Martín Hernández, M. L. (2006). El derecho de los trabajadores a la seguridad y salud en el trabajo. Madrid, España: Consejo económico y social.

Melo Crespo, J. C. (2015). Gestión de riesgo en la organización: teoría y práctica en la empresa. La Habana, Cuba: Editorial Academia.

Montoya Melgar, A., y Pizá Granados, J. (2000). Curso de seguridad y salud en el trabajo (2 ed.). Madrid, España: Editorial Mc Graw Hill.

Montoya Melgar, A. (2017). Derecho del Trabajo (38 ed.). Madrid, España: Editorial Tecnos.

Moreira, M. E. (2003). ¿Qué es la Sociedad? Recuperado de http://www.biblioteca.org.ar/ libros/89004.pdf.

Oficina Nacional de Estadísticas e Información. (2018). Protección del Trabajo. Indicadores seleccionados. Recuperado de http://www.one.cu/publicaciones/03estadisticassociales/ indprotecciontrabajo/proteccion-enero-diciembre17.pdf. 
Organización Internacional del Trabajo [OIT]. (1981). Convenio sobre seguridad y salud de los trabajadores. Recuperado de http://www.ilo.org/dyn/normlex/es/f?p=NORMLEX PUB:12100:0::NO::P12100_ILO_CODE:C155.

Organización Internacional del Trabajo. (2005). Informe de la Conferencia Internacional del Trabajo. Recuperado de https:/www.ilo.org/public/spanish/standards/relm/ilc/ilc93/ pdf/guide.pdf.

Organización Internacional del Trabajo. (2005). Marco de promoción en el ámbito de la seguridad y salud en el trabajo. Recuperado de https://www.ilo.org/public/spanish/standards/ relm/ilc/ilc93/pdf/rep-iv-1.pdf.

Organización Internacional del Trabajo. (2007). Informe de la Conferencia Internacional del Trabajo. Recuperado de https:/www.ilo.org/public/spanish/standards/relm/ilc/ilc96/ pdf/guide.pdf.

Organización Internacional del Trabajo. (2010). Lista de enfermedades profesionales de la OIT. Recuperado de http://www.ilo.org/wcmsp5/groups/public/---ed_protect/---protrav/--safework/documents/publication/wcms_125164.pdf.

Organización Internacional del Trabajo. (2016). Estrés en el trabajo: Un reto colectivo. Recuperado de http://www.ilo.org/wcmsp5/groups/public/---ed_protect/--protrav/---safework/documents/publication/wcms_473270.pdf.

Organización Mundial de la Salud. (2017). ¿Qué es la promoción de la salud? Recuperado de http://www.who.int/features/qa/health-promotion/es/.

Organización de Naciones Unidas. (1948). Declaración Universal de Derechos Humanos. Recuperado de http://www.ohchr.org/EN/UDHR/Documents/UDHR_Translations/ spn.pdf.

Pérez Porto, J. y Merino, M. (2008-2012). Definición de Salud. Definición. de: Wordpress. Recuperado de http://definicion.de/salud/\#ixzz3UZmAOmNf.

Quesada Segura, R. (2015). El empleador y su deber de prevención (III). Sexo y género como factores modalizadores de las obligaciones preventivas. En G. García González y A. Garrígues Giménez (Eds.), Manual de Derecho de la Prevención de Riesgos Laborales (pp. 207-229). Valencia, España: Tirant lo Blanch.

Ramírez Barbosa, P. A. (2007). El delito contra la seguridad y salud en el trabajo. Madrid. España: Iustel. 
Rivero García, D. y Bertot Yero, M. C. (2017). Código Penal de la República de Cuba: Anotado con las disposiciones del Consejo de Gobierno del Tribunal Supremo Popular (3 ed.). La Habana, Cuba: Ediciones onBc.

Salud Ocupacional. (2017). Enciclopedia de Conceptos (versión electrónica). Recuperado de http://concepto.de/salud-ocupacional/.

Sánchez Pérez, J. (2016). Los riesgos psicosociales en el ámbito laboral: una visión global y práctica. Estrés laboral, sindrome del trabajador quemado, acoso laboral y sexual y enfermedades de súbita aparición. Granada, España: Editorial Comares, S.L.

Soto Calderón, J. C. (1961). Derecho penal del trabajo. Santiago de Chile, Chile: Editorial Jurídica de Chile.

Terradillos Basoco, J. M. y Boza Martínez, D. (2017). ElDerecho penal aplicable a las relaciones laborales. Albacete, España: Editorial Bomarzo.

Unión General de Trabajadores. (2011). Riesgos Psicosociales. Recuperado de http://www.ugtbalears.com/es/PRL/Publicaciones/Fichas/16-22 Riesgos\%20psicosociales.pdf. 